\title{
Innovaciones en el cómic digital. El caso de Modern Polaxis
}

\section{Pablo Sánchez de Mora Díaz}

\author{
Recibido: 10.07.2021 — Aceptado: 30.07.2021
}

\section{Titre / Title / Titolo}

Le bande dessinnée digital. Le cas de Modern Polaxis Digital comic innovation. The case of Modern Polaxis Innovazioni nel fumetto digitale. Il caso di Modern Polaxis

\section{Resumen / Résumé / Abstract / Riassunto}

En los últimos años hemos visto cómo el cómic digital ha ido ganando relevancia en todos los sentidos. Cada vez hay más autores que nos proponen diferentes formas de leer cómic, siendo la tecnología una herramienta más para este fin. Sin embargo, el debate acerca de trazar los límites sobre el uso de ciertos recursos como son la animación y el sonido en el cómic digital sigue estando vigente. Modern Polaxis (2014) es una obra que se balancea sobre esta delgada línea al ser un cómic en papel que recurre a la realidad aumentada. Analizaremos este cómic y otros casos para para hablar del presente debate acerca del uso de recursos audiovisuales en el cómic digital.

Ces dernières années, nous avons vu à quel point la bande dessinée a gagné en importance à tous points de vue. Il y a de plus en plus d'auteurs qui proposent différentes manières de lire la bande dessinée, la technologie est devenue le moyen le plus efficace à cet effet. Cependant, se poursuit le débat sur la limitation de l'utilisation de certaines ressources telles que l'animation et le son dans les bandes dessinées. Modern Polaxis (2014) est une ?uvre qui tient compte de cette fine ligne car c'est une bande dessinée sur papier qui utilise la perception augmentée de la réalité. Nous analyserons cette bande dessinée et d'autres cas pour parler du débat actuel sur l'utilisation des ressources audiovisuelles en bande dessinée.

In recent years we have seen how the digital comic has been gaining relevance in every way. There are more and more authors who propose different ways of reading comics, technology has become the most effective tool for this purpose. However, the debate about drawing limits on the use of certain resources such as animation and sound in digital comics continues. Modern Polaxis (2014) is a work that balances on this fine line as it is a comic on paper that uses augmented perception of the reality. We will analyze this comic together with other works to talk about the current debate about the use of audiovisual resources in digital comic.

Negli ultimi anni abbiamo visto come il fumetto digitale ha acquistato rilevanza sotto tutti i punti di vista. Sempre più autori ci propongono diverse forme di leggere un fumetto, essendo la tecnologia digitale un mezzo di comunicazione molto effettivo per questo fine. Ciò nonostante, rimane acceso il dibattito sui limiti dell'uso di certe risorse tecnologiche, come l'animazione e il suono, nel fumetto digitale. Modern Polaxis (2014) è un'opera che si muove su questa linea sottile trattandosi di un fumetto cartaceo che ricorre ad un aumento della percezione. Analizzeremo questo fumetto insieme ad altri testi per trattare il dibattito corrente sull'uso di risorse audiovisuali nel fumetto digitale.

\section{Palabras clave / Mots-clé / Key words I Parole chiave}

Cómic digital, recursos audiovisuales, Modern Polaxis, realidad aumentada.

Digital Comic, instrument audiovisuel, Modern Polaxis, perception augmentée de la réalité.

Digital Comic, audiovisual tool, Modern Polaxis, augmented perception of the reality.

Fumetto digitale, strumenti audiovisuali, Modern Polaxis, aumento della percezione. 


\section{Del cómic digital a la realidad aumentada}

Importantes galardones de la industria del cómic ya cuentan con nominaciones y premios específicos dedicados al cómic digital como los premios Eagle, los Ignatz, los Harvey o los premios Eisner. También algunos de los autores más consagrados se lanzan a explorar este formato, autores de la talla de Chris Ware o el mismísimo Alan Moore.

La necesidad de prestar atención al cómic digital era inminente al ser un fenómeno que crece y que engloba intereses de jóvenes consumidores como pueden ser la animación, la lectura interactiva o la narrativa transmedia.

¿A qué nos referimos cuando hablamos de cómic digital? Nos referimos a una obra creada con la intención de ser leída en un medio digital, ya sea en ordenador, tablet o smartphone. Este término incluye los cómics creados para ser leídos en páginas webs o descargados en PDF, los llamados webcómic; también los encontramos en apps para cualquier tipo de dispositivo, o incluso en las redes sociales. Lo más interesante es que las redes sociales a las que han recurrido muchos autores como Facebook o Instagram no fueron creadas para artistas si no para crear redes de amigos o para fotografías. Las herramientas para recopilar imágenes a forma de álbumes fue un recurso que utilizaron los dibujantes para crear estos webcómics al darles la posibilidad de colocar imágenes o dibujos sucesivamente. Algunos artistas consiguieron con esta técnica gran reconocimiento a nivel mundial como Simon Hanselmann, Power Paola o Joan Cornellá. Pronto recopilarían todo su trabajo en sus respectivos blogs, creándose una generación de autores que encontrarían en el webccomic y las redes sociales los lugares donde dar a conocer sus primeros trabajos.

Los avances tecnológicos y la ambición creativa de los autores han llevado este formato a poder combinarlo con el cómic tradicional. Crear historias que puedan ser leídas tanto en pantalla como en papel simultánea- mente es un hecho gracias a la realidad aumentada. El autor australiano Stuart Campbell, también conocido como Sutu, se lanza en el año 2014 a experimentar con este recurso en su obra Modern Polaxis. Previamente ya habían utilizado estos recursos algunos autores como François Schuiten en su obra La Doce (2012) o incluso Marvel adaptando alguno de sus cómics ya existentes como Avengers vs. X-Men \#1.

La sinergia entre el cómic y la tecnología lleva siendo un interesante terreno de cultivo desde los años noventa. La democratización tecnológica ha ayudado a que muchos autores se lazaran a crear cómics con la intención de ser leídos en la pantalla. El experto en webcómic Shaenon Garrity (2011) coloca el punto de partida del cómic digital con la obra de Eric Monster Millikin, Witches in Stitches (1985), siendo concebida para distribuirse vía mail. Otro caso similar fue el de Joe Ekaitis con su obra digital T.H.E. Fox (1986). Finalmente en 1993 se crea la primera web creada con el objetivo de publicar un cómic, siendo el caso de Doctor Fun creado por David Farley. Pronto autores se sumaron a este nuevo formato como Charley Parker con su exitoso webcómic Argon Zark!! (1995), todavía vigente.

El formato digital se asienta con la publicación del ensayo Reinventig comics (2000) de Scott McCloud. El autor americano profundiza acerca de las ventajas y variaciones que podrían alterar nuestra percepción de cómic a causa de la tecnología. Entre estas ventajas se encuentran la facilidad de difusión mediante Internet, la libertad creativa, la incorporación de recursos audiovisuales o la inmediatez de publicación entre muchas otras. Pero uno de los atributos del formato en los que más incide el autor y divulgador americano es la capacidad de crear con total libertad cualquier tipo de páginas y viñetas al no tener que estar subordinado al papel. A este recurso lo denomina infinite canvas (lienzo infinito), con el que señala la posibilidad que nos da el cómic digital de crear sin estar encorsetado a unas dimensiones determinadas. Otra de las innovaciones que plantea acerca de la influencia que llevaría a cabo la tecnología sobre el cómic es la convergencia de técnicas digitales con los procesos de creación habituales: 
En comparación con los últimos avances en otros campos (como el trabajo en red), podría parecer que el dibujo generado por ordenador se hubiera estancado, pero creo que solo acabamos de empezar. / En los próximos 20 años se producirán cambios radicales en cómo los ordenadores procesan las imágenes, cómo las manipulamos y cómo vinculamos arte y tecnología. / Un cambio que ya está en marcha es la tendencia a tender puentes entre los «programas de dibujo« orientados a objetos y los mapas de bits de los programas de «pintura«, basados en píxeles. / [...] / Los artistas digitales son codiciosos. Lo quieren todo y saben que lo obtendrán lo suficiente. La supuesta disyuntiva entre la potencia de la informática y las espontaneidad del lápiz y la tinta solo es una coyuntura temporal. / Los avances en software y hardware devolverán la espontaneidad a los artistas en menos de una década. (McCloud, 149).

Este ensayo se convierte en un punto de inflexión en el cómic digital, ya que no sólo habla de la importancia en el cómic de la inclusión de nuevos recursos tecnológicos, si no de los cambios en la narrativa y en la forma de contar una historia en el cómic digital. Pronto empiezan a surgir cómics que recurren a animaciones y sonidos o a la interacción con el lector, creando experiencias de lectura nunca vistas. Algunos ejemplos son obras como Touch Sensitive (2011) de Chris Ware o Florence (2018), del colectivo Mountains Studio, donde se usan. La interacción puede llevarse a cabo de muchas maneras, puede ser a través de tocar la pantalla táctil de una teblet o del móvil desplazando elementos de las viñetas, con el scroll del ratón del ordenador o clicando. Lo interesante de la interacción en el cómic digital son los diferentes momentos en los que se utiliza. Hay una gran diversidad de oportunidades donde los autores hacen un llamamiento al lector para participar durante la lectura creando una lectura mucho más activa y entretenida, sobre todo para los más pequeños. Otras obras como Phallaina (2016) de Marietta Ren (Imagen 1) usan la animación para evocar a ciertas sensaciones relacionadas con la historia. Ciertos recursos animados pueden ser las imágenes en bucle, movimientos la luz creando cierto ambiente o la aparición y desaparición de peces y otros seres marinos con el objetivo de expresar los brotes epilépticos de la protagonista.

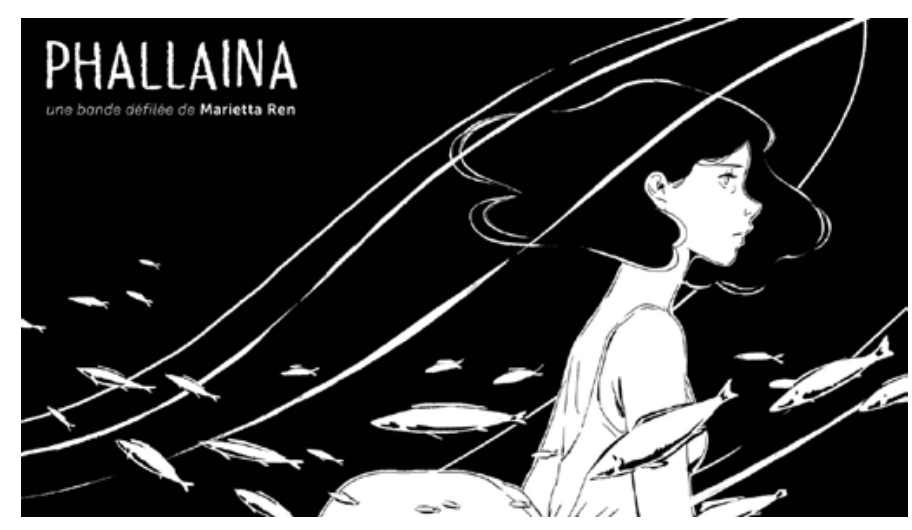

Imagen 1. Phallaina, Marietta Ren (2016)

El uso de este tipo de aplicaciones en el cómic digital era algo inminente como ya predijo Scott McCloud (2000). Sin embargo, el cómic digital que recurre al hipertexto pone en riesgo la estructura de lo que conocemos como cómic, ya que impide una visión general de las viñetas conforme las vamos leyendo. Esta confrontación entre los fundamentos del cómic y las innovaciones que nos aporta la tecnología puede causar verdaderos quebraderos de cabeza:

El hipertexto se basa en el principio de que nada existe en el espacio. Todo es aquí o no aquí, mientras que en el mapa temporal de los cómics, todo elemento del trabajo tiene siempre una relación espacial con todos los demás elementos. Desmenuzar un cómic en imágenes por separado supondría destrozar completamente ese mapa y, por tanto, también el tejido que forma la identidad básica de los cómics (McCloud, 219).

Este formato no excluye a la secuencialidad, pero está claro que van perdiendo características significativas del cómic tradicional, aunque también aporte otras nuevas. El cómic digital da rienda suelta a la exploración, pero a veces llegamos a límites que tienen más que ver con otras disciplinas que con el cómic. Es el caso por ejemplo de los bypercomics, un tipo de cómic digital caracterizados por ser narrativas alterables según vayas interactuando con los elementos del cómic. Al incluir animaciones, sonidos y diversas narrativas estaríamos hablando más de videojuegos que de cómics, pero ya hablaremos de estos medios posteriormente. 
Todos estos híbridos de diferentes formatos y plataformas se han ido generando en prácticamente todas las disciplinas artísticas y culturales como en la animación independiente, la música o el teatro desde inicios del siglo XX con la llegada de Internet. Que hoy en día se haya normalizado la lectura de cómics en cualquier pantalla era algo de lo que hablaba Henry Jenkins en su obra La cultura de la convergencia de los medios de comunicación (2008). La convergencia mediática viene a ser un proceso de migración de diferentes disciplinas culturales hacia otros medios en los que nunca antes se habían consumido. Este concepto es fundamental para entender la obra de Modern Polaxis. El autor de esta obra pertenece a una generación de artistas que proceden de otras disciplinas (concretamente del arte digital 3D) y deciden experimentar con el cómic como con otros tantos medios.

Gracias a propuestas arriesgadas se han conseguido dar ciertos pasos muy relevantes a la hora de innovar narrativamente en este formato. Poco a poco se han ido llevando a cabo proyectos de una forma colectiva entre autores y estudios de diseño o animación que han asentado las bases del cómic aumentado. Alguno de estos estudios son Magic Leap, EigoManga o Anomaly Productions, todos de Estados Unidos.

\section{Modern Polaxis: una historia a dos bandas}

Nuestro autor protagonista, Stuart Campbell (1981) o también conocido como Sutu, es un artista gráfico especializado en crear historias interactivas en realidad aumentada. Tras publicar diversos web cómics Nawlz (2008) y Neomad (2013) y su fanzine Krysalis (2014), se lanza a publicar su primer cómic aumentado, Modern Polaxis, en 2014. Mediante crowdfunding consigue financiar este proyecto en el que participarán los estudios de VFX Lone Coconut, el programador Lukasz Karluk y con el sonido de Lhasa Mencur. Su primera obra, Nawly, consta de 14 capítulos en los que narra una aventura $c y$ berpunk en un universo futurista donde ocurren peleas, conspiraciones, misterios futuristas, consumo de drogas y demás experimentos. Neomad es un cómic digital de tres episodios donde el autor cuenta la historia de un grupo de jóvenes (inspirados en aborígenes australianos) en el 2076 que serán decisivos en la salvación del planeta. Viajan por el universo para afrontar esta misión acompañados por robots y demás personajes extraterrestres.

Modern Polaxis se desarrolla simultáneamente en dos formatos. Primero tenemos el formato físico, un cómic de 50 páginas en cuatricromía y encuadernado en wireo. Por otro lado, tenemos el formato digital al que se accede mediante una app en el móvil o tableta. En cada página, a través de la app y la cámara, el dispositivo mostrará la página que vemos en papel con alteraciones audiovisuales o incluso elementos totalmente diferentes. Crea una doble lectura, el texto e imágenes del formato físico y la parte audiovisual (aunque también incluye texto adicional) en el dispositivo. Algo muy importante a la hora de tratar sobre este formato híbrido es que el contenido digital siempre está subordinado al contenido del cómic en papel. Scott McCloud hace referencia a este aspecto en Reinventar el Cómic:

$\mathrm{Al}$ combinar los estilos, géneros y recursos del cómic impreso con los efectismos interactivos de los juegos multimedia los creadores esperaban dar vida al cómic. [...] Calidad relativa a parte, las estrategias aditivas eludían la evolución del propio cómic al convertirlo en una masa indigesta en el estómago del fenómeno multimedia sin llegar nunca a sus ideas esenciales. [...] La meta de «dar vida« al cómic parece más próxima en las obras que crean una experiencia envolvente a base de sonido, movimiento e imágenes. [...] La promesa implícita en la idea de la Realidad Virtual es el destino final del viaje colectivo que los narradores han emprendido a lo largo de la historia. / La auténtica RV, tal y como la concibe la mayoría, tiene un pequeño problema: ¡no existe todavía! / Aun así, la enorme difusión de la promesa de la Realidad Virtual ha ejercido una influencia tan poderosa que otros medios ya han empezado a doblegarse para intentar llenar a la carrera el vacío que, algún día ocupará esta nueva tecnología. [...] Al final, la RV reclamará su lugar, llenará el vacío y los medios restantes, tras haber perdido parte de sus funciones originales volverán a erguirse y redescubrir la fuerza de sus raíces (McCloud, 209). 


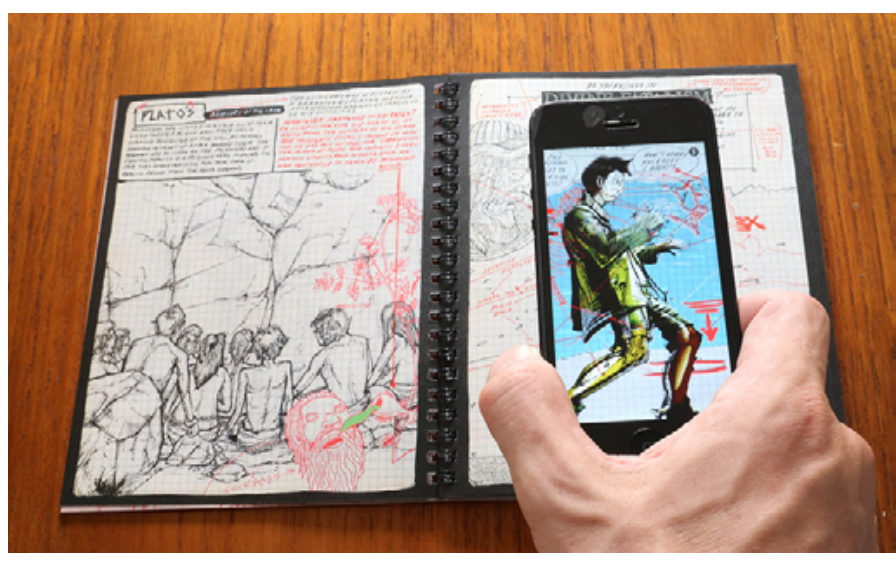

Imagen 2. Modern Polaxis, 2014

La historia cuenta cómo Polaxis, el protagonista, descubre como adquiere capacidades para viajar a través del espacio y del tiempo a través de una modificación de sus genes. Emprenderá un viaje lleno de psicodelia, momentos de esquizofrenia y brotes psicóticos con el objetivo de conocer a acerca de su condición.

$\mathrm{El}$ autor recurre a un argumento en el que puede explorar la realidad aumentada con total libertad, usando la percepción de la realidad del protagonista y su imaginación como contenido para aplicarlas en el formato digital. Dicha narrativa encaja a la perfección con lo que nosotros podemos entender de cómo es la lectura con realidad aumentada. Cuando nos enfrentamos a esta forma de leer puede crear cierta incomodidad al pasar de leer en papel al dispositivo móvil constantemente debido a su doble lectura. Sin embargo, cuando nos adentramos en la historia, comprendemos la razón por la que el autor ha recurrido a esta tecnología y a este formato híbrido. El protagonista cuenta sus viajes astrales, brotes psicóticos, alucinaciones en reuniones con chamanes y demás situaciones ficticias que crean una necesidad de alternar lo real y lo que se imagina constantemente. Esta sensación de salto entre los dos planos creada por la realidad aumentada añade una interesante inmersión en la historia que, a su vez, aporta cierto sentido. Ver cómo el autor utiliza este recurso y el cómic aumentado, no como un alarde tecnológico y de efectos visuales, si no con un sentido narrativo ayuda

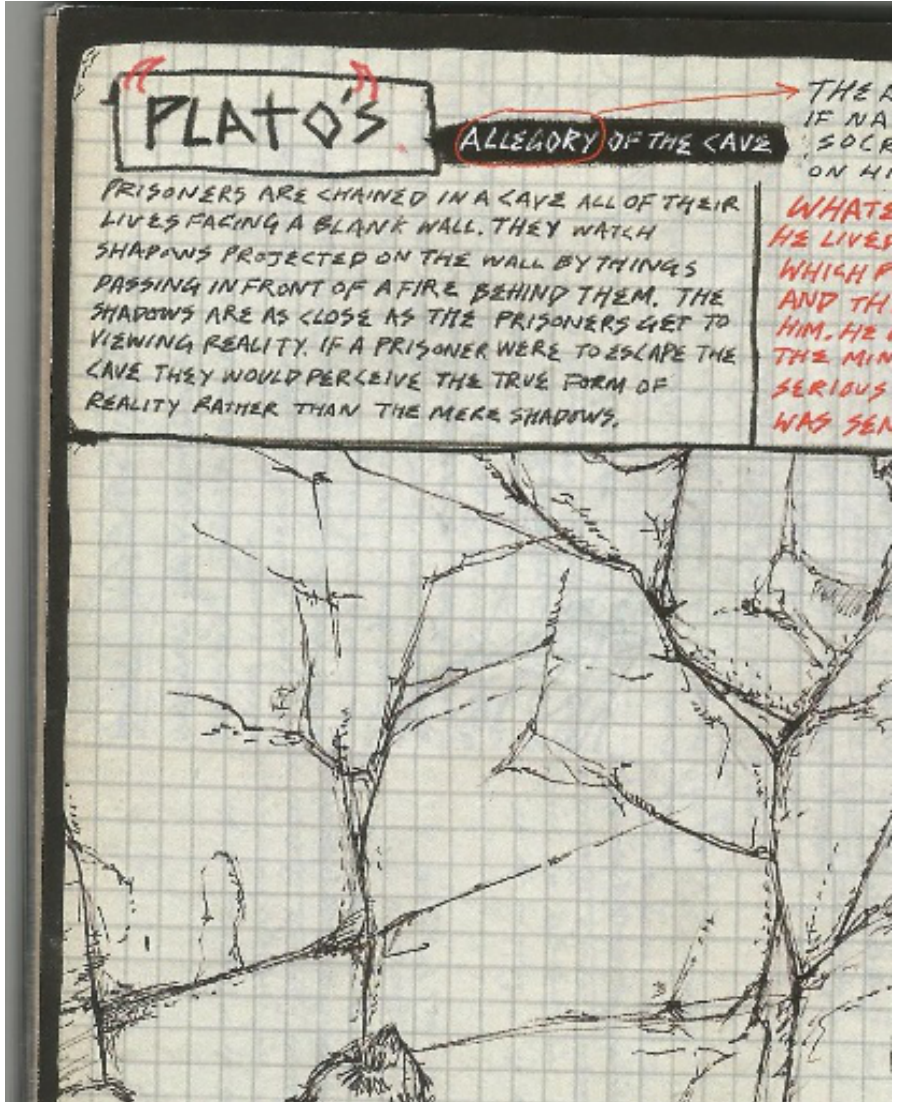

Imagen 3. Modern Polaxis, 2014. Página 1

a tomar en consideración el cómic aumentado como un formato a tener en cuenta. Hablamos de cualquier situación narrativa que contemple ciertas situaciones simultáneas donde el cómic aumentado puede tener cabida y un gran potencial. Algunas de estas situaciones pueden ser flashbacks, multiversos, idas de conciencia, personajes conectados, exploraciones en el subconsciente, introspectivas emocionales en el interior de los personajes...La realidad aumentada es un recurso muy válido para crear varias capas narrativas simultáneamente, algo que está bastante en auge actualmente en disciplinas como el cine, series o en los videojuegos.

La obra utiliza elementos característicos del ciberpunk y de la ciencia-ficción moderna, recordándonos a películas y cómics como Matrix (1999), Ghost in the Shell (1995) o Transmetropolitan (1997). Comienza explicándonos el mito de la caverna de Platón, poniendo 


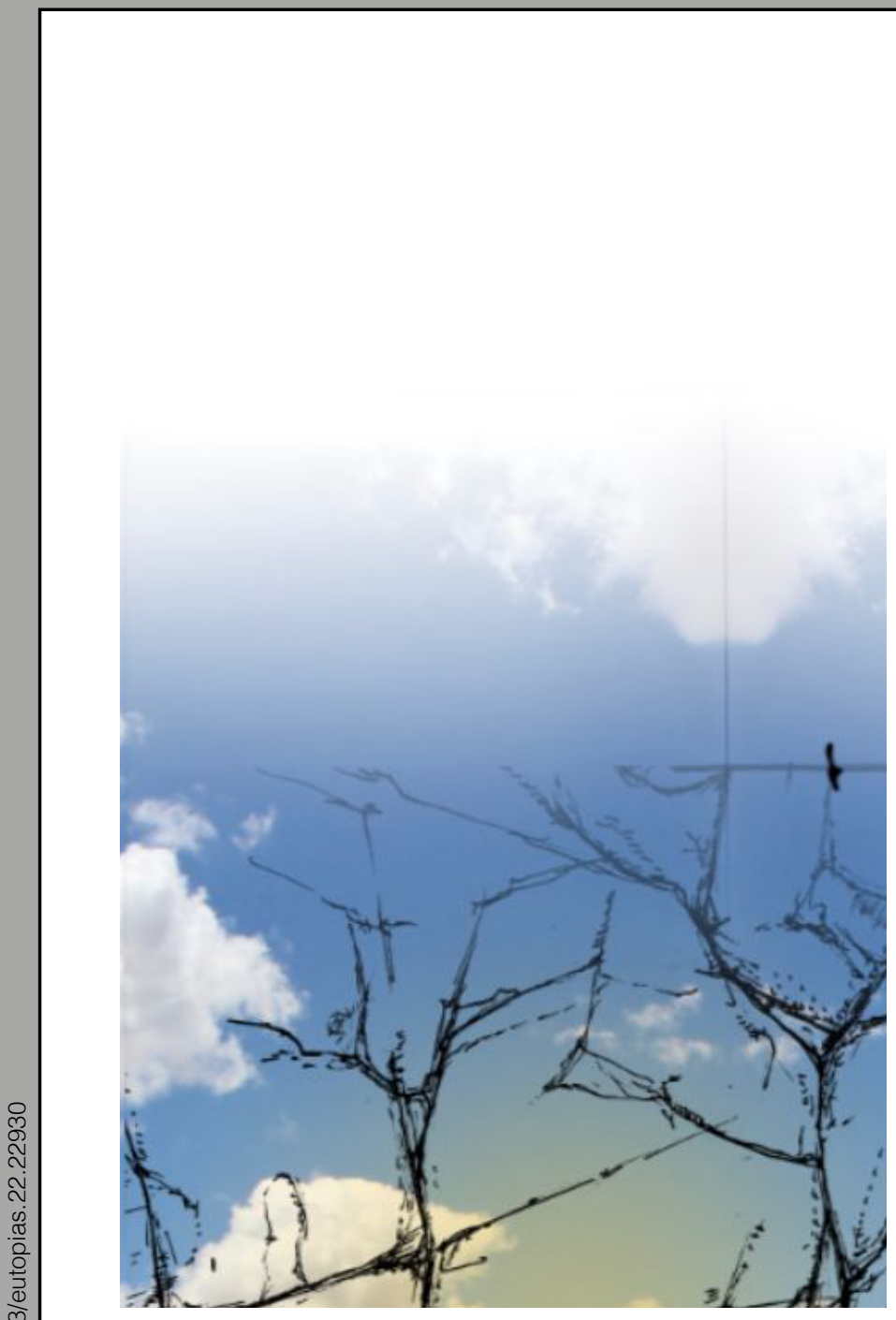

Imagen 4. Modern Polaxis, 2014. Página 1.

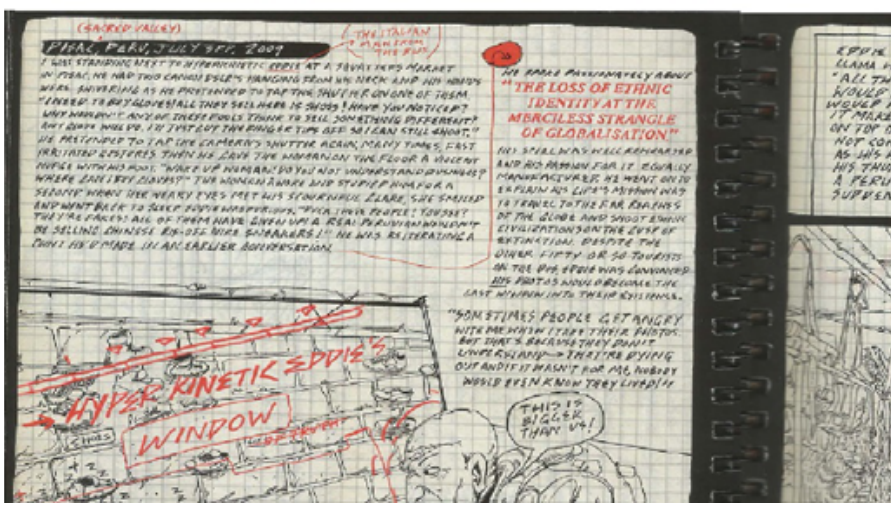

en evidencia las dos realidades que van a experimentar tanto el protagonista como el lector durante la historia. Esta introducción nos presenta cómo la narración se construye en base a lo que le pasa al protagonista y a la interpretación de su experiencia con los sucesos que van ocurriendo:

\section{Página 1:}

\section{Plato's allegory of the cave.}

Prisoners are chained in a cave all their lives facing a blank wall. They watch shadows projected on the wall by things passing in front of a fire behind them. The shadows are as close as the prisoners get viewing reality. If a prisoner were to escape the cave would perceive the true form of reality rather than the mere shadows. (Sutu, 2014) ${ }^{1}$

\section{Página 1 en Realidad Virtual:}

If you're reading this you've obviously discovered 'the lens'. You can see the shadows on the wall and you are aware that someone or something is casting them. Let's not share drinks with Socrates. Let's find the projector and destroy it. (Sutu, 2014) $)^{2}$

La estética de cómic underground americano clásico consigue darle una apariencia de obra naíf y sin ambición por conseguir una estética limpia y sublime. Sin embargo, al estar en un formato cercano al fanzine clásico, con encuadernación en wire-o y páginas cuadriculadas nos da a entender que el cómic es en realidad el cuaderno del protagonista, siendo un aspecto que le da originalidad a la obra. A parte de la estética y el formato, la cantidad de garabatos y anotaciones evidencia que efectivamente se puede tratar de un cuaderno de viaje. Si nos centramos en la gráfica del formato en papel encontramos un gran dinamismo en la lectura causado por la disposición de muchos elementos que complementan a la historia. Podemos encontrar en varias escenas que confluyen tanto mapas, explicaciones gráficas sobre ciertos artilugios o infografías que cuentan teorías conspiranoicas. Sin embargo, a pesar de que la riqueza gráfica de la obra es muy variada, el exceso de

Imagen 5. Modern Polaxis, 2014. Página 1 en Realidad Virtual. 
texto de forma generalizada perjudica la experiencia de lectura seriamente.

Si hablamos de la parte digital, encontramos una dimensión visual donde el color y la animación cobra un protagonismo en la historia. Como comentábamos, aquí encontramos ciertos pensamientos del protagonista acerca de lo que va ocurriendo, pasando el texto a un segundo plano. El autor deja el formato virtual para la contemplación de las animaciones que complementan a la trama como pueden ciertos pensamientos del protagonista, percepciones personales, imaginaciones y delirios.

Pese a que consiguió gran éxito con la preventa y la financiación vía crowfunding, no consiguió llegar a grandes medios especializados en cómics salvo excepciones, como por ejemplo el medio web británico Pipedream comic $^{3}$ o Comic Book Resources ${ }^{4}$. Sin embargo, los medios relacionados con tecnología, diseño 3D, videojuegos y cultura digital sí que tuvieron cierto interés por contar acerca de esta obra. Algunos de los medios digitales que profundizaron un poco más a la hora de dar a conocer esta obra fueron Digital Trends ${ }^{5}$, BleedingCool6 o Upload7. Además, el propio Scott McCloud ya se refirió a esta obra como: «Another mind-bending creation from Sutu, the creator of Nawlz: ${ }^{8}$.

Fue en sus siguientes publicaciones cuando Sutu consiguió reconocimiento por parte de las instituciones y medios relacionados con el cómic, sobre todo al conseguir estar nominado al mejor webcomic en los Premios Eisner de 2016 con su obra These Memories Won't Last (2016). También ha conseguido reconocimientos honoríficos por parte de los premios Webbys, presentados por la Academia Internacional de Artes y Ciencias, como mejor obra digital y también por la Japan Me-

\footnotetext{
https://pipedreamcomics.co.uk/interview-situ-augmented-reality-in-modernpolaxis/

https://www.cbr.com/modern-polaxis-travels-through-time-augmented-reality/ https://www.digitaltrends.com/cool-tech/modern-polaxis-augmented-realitycomic-book/

${ }^{6}$ https://bleedingcool.com/comics/modern-polaxis-a-modern-augmented-reality-comic/

https://uploadvr.com/augmented-reality-comic-books-polaxis/

«Otra creación alucinante de Sutu, el creador de NAWLZ« - Scott McCloud.
}

dia Arts Festival como mejor artista digital por la obra Nawly en 2013.

\section{Formas de lectura: a través del papel o en el formato digital}

La búsqueda de nuevas formas de leer los cómics lleva décadas siendo una honda preocupación entre muchos autores que tratan de sintonizar con nuevos lectores y beneficiarse de las posibilidades expresivas de los formatos. La variedad de recursos a la hora de conseguir una experiencia de lectura original es de lo más diversa. Me estoy refiriendo al concepto de original reading anglosajón que busca consolidar nuevas audiencias ofreciendo experiencias únicas. Una de las primeras obras que inicia esta tendencia es Batman 3D (1990) de John Byrne. Esta novela gráfica fue creada por dicho autor con la intención de ser leída con unas gafas 3D incluidas, consiguiendo una obra realmente innovadora por aquel entonces. Siguiendo la estela de este formato, también tenemos el cómic de SVK (2011) de Warren Ellis y D'Israeli's, en el que encontramos una historia oculta que podemos desvelar aplicando luz ultravioleta. Otra obra que juega con este tipo de mecanismos es Polychromie (2014), una obra colectiva de quince autores donde cada autor crea dos historietas simultáneas: una en rojo y otra en azul. Gracias a los dos filtros que incluye, uno rojo y otro azul, podremos leer cada historia. En estos últimos dos ejemplos al fin y al cabo no dejan de ser experiencias similares a la de Modern Polaxis, simplemente en esta obra se utilizan recursos digitales y en las obras anteriores se utilizan recursos analógicos.

La realidad aumentada ya se ha convertido en una herramienta más para leer cómics. Ha sido utilizada en diversas ocasiones para conseguir combinar la lectura tradicional en papel y la lectura de viñetas animadas que complementan a la historia en dispositivos móviles. La realidad aumentada podemos definirla como la combinación de elementos virtuales con el espacio físico real (Milgram y Kishino, 1994). La definición de este con- 


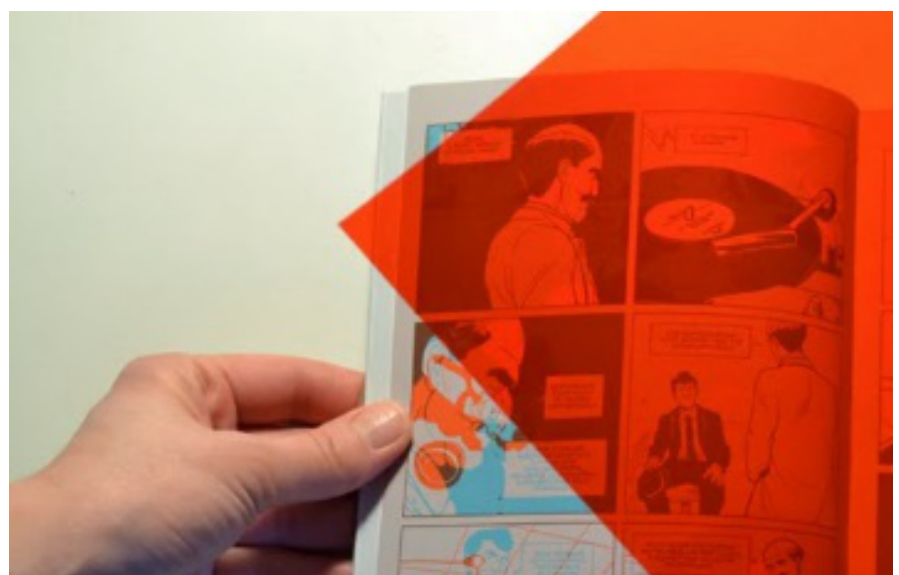

Imagen 6. Polychromie, 2014.

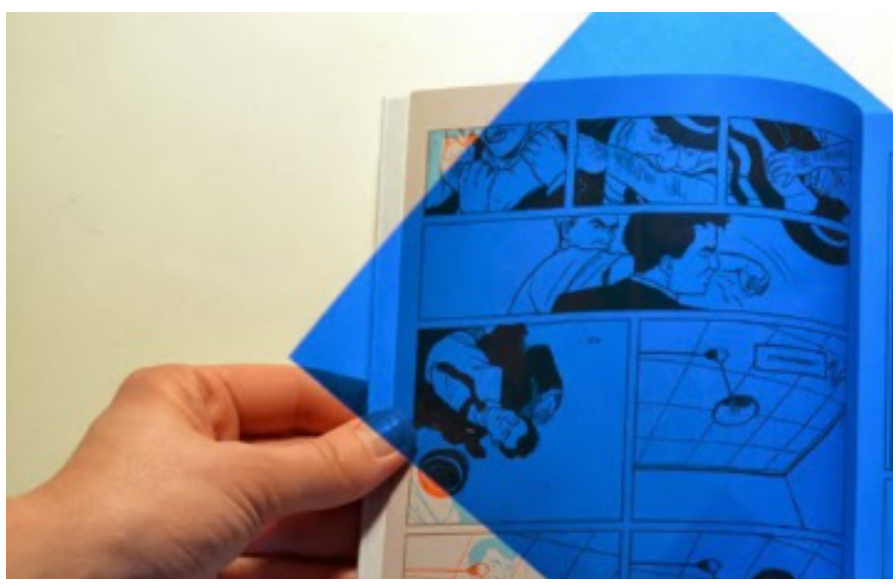

Imagen 7. Polychromie, 2014. cepto lo matizaría Azuma (1997), considerando la realidad aumentada como la experiencia que permite al usuario ver el mundo real mientras se superponen objetos virtuales en el mismo espacio. No hay que confundirla con realidad virtual, ya que ésta consiste en la inmersión del usuario en un entorno virtual a través de un dispositivo que cubrirá nuestra cabeza (Head Mounted Displays, $H M D)$. Es necesario matizar que el tipo de realidad aumentada a la que nos estamos refiriendo se define como «realidad aumentada enriquecida«. Este término hace referencia a la forma de generar elementos virtuales, concretando que se realizan a través de dispositivos móviles y codificando con la cámara estas animaciones o imágenes de cualquier tipo en la pantalla. También se conoce como realidad aumentada screen-based.

Algunos ejemplos de los cómic que han adoptado esta forma de contar historias son La Doce (2012), de François Schuiten o Binary Land «Hello World!!!» (2012), de Baptiste Milési, Julien Milési y Raphaël Munoz. También Marvel puso en marcha la realización de cómics con realidad aumentada, pero simplemente fue una labor de adaptar al formato digital ciertos cómics donde incluían animaciones en 3D y material audiovisual. La capacidad que tiene la realidad aumentada para crear una experiencia narrativa totalmente envolvente y dinámica ha generado cierto reclamo. Un factor clave también por la que autores se han decidido en desarrollar la realidad aumentada para aplicarlo al cómic ha sido la doble lectura que surge a través del cómic en papel y las imágenes digitales que aparecen en el dispositivo. La realidad aumentada consigue ser un medio realmente potente para contar aspectos inquietantes y muy nítidos sobre la influencia de las drogas y las emociones del protagonista. Alternar las animaciones en nuestro dispositivo con el papel nos ayuda a entender las alucinaciones que sufre y las forma en las que fluyen según avanza la historia. Esto es algo totalmente necesario a la hora de usar la realidad aumentada, el uso de este recurso debe ir acorde a la historia y aportar sentido a lo que estamos contando.

En el momento de hablar de la relación de la realidad aumentada y el cómic, no podemos dejar atrás el hecho

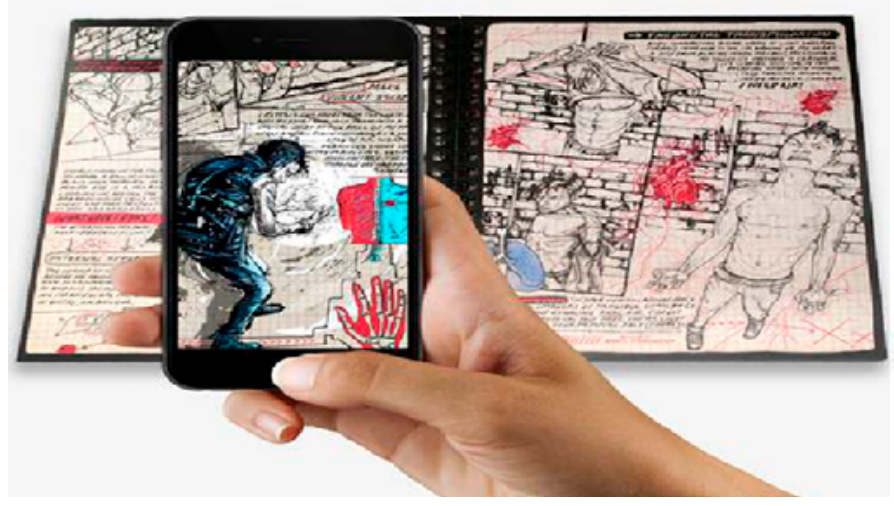

Imagen 8. Modern Polaxis, 2014. 
de que las animaciones digitales deben siempre aparecer para dar un sentido narrativo a la historia. No tendría ningún sentido que la utilizáramos para crear animaciones independientes al cómic. El cómic y el contenido digital deben ir a la par y de forma alterna o simultánea. Es fundamental que la realidad aumentada también funcione como arte secuencial, es decir, que pese a utilizar animaciones en movimiento, se siga conservando la narrativa a través de viñetas y el lector pueda decidir avanzar en la historia y no la propia animación.

Will Eisner ya nos hablaba de este factor esencial a la hora de saber qué es un cómic. Por eso explica la importancia de la cooperación del autor con el lector para crear una experiencia a través de las imágenes y el texto. Si no hay textos, ni imágenes secuenciales y solo tenemos animaciones, no tendremos un cómic.

«Escribir« cómics puede definirse como la concepción de una idea, la disposición de los elementos gráficos, la construcción de la secuencia de dicha narración y la composición de los diálogos. Es, a un mismo tiempo, parte y todo del medio. Es una habilidad especial, cuyos requisitos no suelen ser los de otras formas de escritura, pues está relacionada con una técnica particular. [...] En el arte secuencial, ambas funciones (dibujar y escribir) se encuentran irrevocablemente entrelazadas. El arte secuencial es el acto de tramar un tejido. (Eisner, 1996).

El ritmo es un elemento esencial en el cómic, por ello es importante que en el cómic digital no sean las animaciones las que determinen el ritmo, sino que lo haga el conjunto de las viñetas, aunque estas contengan animaciones. El lector debe ser siempre quien elija el ritmo de lectura, por lo que las animaciones no deben interrumpir el flujo de la lectura tanto de las viñetas como del texto.

No podemos dejar de tener en cuenta el hecho básico de que el arte secuencial es un medio literario que narra mediante la disposición de imágenes y texto en una secuencia inteligible. Sea cual sea el medio de transmisión, los requisitos fundamentales del arte secuencial siguen siendo los mismos. (Eisner, 1996).

Estas cualidades se respetan a la perfección en $M o$ dern Polaxis. Esto solo se puede conseguir mediante una coordinación correcta de las animaciones según vamos leyendo las páginas, siendo animaciones sugerentes y llamativas que no entorpecen la lectura. En las únicas ocasiones donde podemos dar rienda suelta a lo audiovisual sin interferir en las bases del cómic son en las llamadas splash-pages, pero siempre que consista en realzar el momento que representa, sin llegar a avanzar en la historia. Las splash-pages se pueden considerar como páginas en las que una única viñeta ocupa la mayor parte de la página, siendo un recurso para el alarde pictórico o para dedicar especial atención a un momento decisivo de la trama. El maestro Will Eisner habla del potencial de las splash-pages tal que así:

La primera página de una historia funciona como introducción. Lo que contenga o lo que ocupe depende del número de páginas que sigan. Es una plataforma de lanzamiento para la narración y en muchas historietas establece un marco de referencia. Si se emplea debidamente, captará la atención del lector y le preparará para los acontecimientos que le esperan. Crea un «clima». Cuando el dibujante la diseña como unidad decorativa, se convierte en una página de presentación más que en una primera página. (Eisner, 1985)

La realidad aumentada es un complemento idóneo para elevar el cómic a otro plano, pero hay que tener en cuenta cómo utilizarla y siempre respetando las bases del arte secuencial.

\section{Conclusiones}

La flexibilidad de un formato tan heterogéneo como es el cómic digital puede llegar a crear formatos que se desligan a lo que conocemos como cómic. Recurrir a formatos híbridos y concretamente el cómic aumentado es una fórmula que aportará nuevas narrativas realmente interesantes y los motivos para seguir prestando atención a estas obras son diversos. Principalmente la forma de contar una historia a través de dos planos, uno en papel y otro en digital, puede llegar a ser un recurso que genere importantes innovaciones narrativas. También que existan obras que abran puer- 
tas a aportar animaciones y otros recursos digitales sin perder el formato en papel es un factor que puede ser importante para crear interés en nuevos lectores, sobre todo los jóvenes. Quizás para los viejos lectores asiduos del cómic es algo irrelevante, pero estos recursos pueden servir para conectar con nuevas generaciones de lectores, ya sean infantiles o juveniles. Otro motivo importante es destacar la fuerza de estos cómics aumentados y su capacidad de transmitir tramas a través de lo audiovisual y que por ello consigan arrastrar con ímpetu al lector dentro de la historia. Estas características pueden aportar elementos muy originales al cómic, aunque es muy probable que lleguen nuevos recursos y nuevas formas de enfrentarse a nuevos experimentos narrativos conforme se vaya desarrollando.

No podemos terminar estar revisión sobre el cómic aumentando sin poner sobre la mesa la posibilidad de que la realidad aumentada pueda terminar siendo un elemento irrelevante de la misma forma que el 3-D lo ha terminado siendo para el cine. Pero, al fin y al cabo, en el presente estos recursos digitales están consiguiendo enriquecer el medio, aunque tengan una intención más de experimentar que de trascender.

\section{Bibliografía}

Azuma, Ronald T. «A Survey of Augmented Reality». Presence: Teleoperators and Virtual Environments, 6, 1997, pp. 355 - 385.

Eisner, Will. La narración gráfica. Barcelona: Norma Editorial, 1996.

Eisner, Will. El comic y el arte secuencial. Barcelona: Norma Editorial, 1985.

Garrity, Shannon. The History of Webcomics. The Comics Journal, 2011.

Jenkins, Henry. La cultura de la convergencia de los medios de comunicación. Barcelona: Editorial Paidós, 2008.

Molina Fernández, Margarita. «Imagen, movimiento e interactividad en el cómic digital». EME Experimental Illustration, Art \& Design, 7, 2019, pp. 44-51. https://doi.org/10.4995/eme.2019.11360.

McCloud, Scott. Reinventar el cómic. Barcelona: Planeta Cómic, 2000.

Milgram, Paul; KISHINO, Fumio. «A Taxonomy of Mixed Reality Visual Display». Institute of Electronics, Information and Communication Engineers (IEICE), vol. E77-D, no 12, 1994, pp. 1321-1329.

V.V.A.A, Asociación de Críticos y Divulgadores de Cómic de España. Cómic digital hoy. Una introducción en presente. Editado por ACDCómic, 2016. 